\title{
Hypovitaminosis D in an Italian population of healthy subjects and hospitalized patients
}

\author{
Elisabetta Romagnoli ${ }^{1}$, Patrizia Caravella ${ }^{2}$, Liliana Scarnecchia ${ }^{3}$, Paolo Martinez ${ }^{1}$ and \\ Salvatore Minisola ${ }^{2 *}$ \\ ${ }^{1}$ Ospedale San Giovanni Battista, Via L. E. Morselli 48, 00100, Rome, Italy \\ ${ }^{2}$ II Clinica Medica, Università degli Studi 'La Sapienza', Viale del Policlinico 155, 00100, Rome, Italy \\ ${ }^{3}$ Laboratorio Analisi, Azienda Ospedaliera San Camillo-Forlanini, Via Portuense 332, 00100, Rome, Italy
}

(Received 30 April 1998 - Revised 27 August 1998 - Accepted 1 September 1998)

\begin{abstract}
The present study aimed to investigate the prevalence and seasonal variation of hypovitaminosis D (defined as serum 25-hydroxyvitamin D level below $30 \mathrm{nmol} / \mathrm{l}$ ) among healthy subjects and hospitalized patients living in central Italy. We studied 297 subjects, 131 in February 1997 and 166 in July 1997, subdivided into four groups: (a) young healthy blood donors; (b) healthy postmenopausal women; (c) inpatients with various medical diseases and (d) inpatients engaged in long-term rehabilitation programmes because of various neurological disorders. In all subjects and patients serum levels of 25-hydroxyvitamin $\mathrm{D}$ were measured by radioimmunoassay. We found a significant seasonal variation $(P<0.0001)$ of serum 25 -hydroxyvitamin $\mathrm{D}$ levels, mean values being higher in summer in all groups, except in patients with a longer hospitalization time (group (d)). In each group, a significantly higher prevalence of hypovitaminosis D was found in winter compared with summer time $(P<0 \cdot 001)$, being unexpectedly high in postmenopausal women (winter $32 \%$ and summer $4.5 \%$ ); furthermore, in both seasons, inpatients were characterized by the highest incidences of hypovitaminosis, particularly those in group (d) (winter $82.3 \%$ and summer $57.8 \%$ ). The results of the present study emphasize the importance of 25-hydroxyvitamin D measurement, and the need to increase vitamin D intake in Italy; foodstuff fortification and supplement use must be considered in order to prevent negative effects of vitamin D deficiency on skeletal integrity.
\end{abstract}

Vitamin D: Skeletal integrity: Hypovitaminosis D

In recent years, a growing interest has developed in the role of the vitamin D-endocrine system interaction in the pathogenesis of bone loss and osteoporosis. While it is well known that severe and protracted vitamin D deficiency leads to osteomalacia, the impact and consequences on bone remodelling of subclinical vitamin $\mathrm{D}$ deficiency remain controversial (Parfitt et al. 1982; Woitge et al. 1998).

Sunlight exposure and diet are the main determinants of vitamin D status, but each is greatly influenced by a variety of factors such as age, race, geographical location, seasons and use of sunscreen (Fraser, 1995). As a consequence, epidemiological studies on vitamin D status, usually defined by the amount of circulating 25-hydroxyvitamin D (25(OH)D) (Hollis, 1996), have shown marked differences between countries. In fact, the prevalence of hypovitaminosis D is lower in North America where sunshine exposure is adequate and the food is vitamin D-fortified, and higher in most European countries, independent of geographical location (McKenna, 1992; van der Wielen et al. 1995; Chapuy et al. 1997). Nevertheless, it has been demonstrated that vitamin D deficiency (defined as a serum $25(\mathrm{OH}) \mathrm{D}$ level below $30 \mathrm{nmol} / \mathrm{l})$ is very common worldwide in the elderly (McKenna, 1992; Keane et al. 1995; van der Wielen et al. 1995; Chapuy et al. 1996, 1997; Jacques et al. 1997), especially if hospitalized (Goldray et al. 1989) and/or institutionalized (Komar et al. 1993; Gloth et al. 1995; Liu et al. 1997). This may occur as a result of low dietary intake that is not compensated for by an adequate exposure to sunlight. Moreover, the decline of renal function with age can lead to reduced serum levels of 1,25-dihydroxyvitamin $\mathrm{D}$ and impaired intestinal $\mathrm{Ca}$ absorption (Akesson $e t$ al. 1997), even if this finding is not universally recognized (Sherman et al. 1990). Vitamin D deficiency, through secondary hyperparathyroidism, could play a significant role in decreasing femoral bone density and increasing bone fragility and fracture risk in the elderly (Quesada-Gomez 
et al. 1996). Moreover, it has been demonstrated that an adequate vitamin D status is important in the maintenance of bone density even in peri- and postmenopausal women (Villareal et al. 1991; Khaw et al. 1992). Therefore, estimation of vitamin D status is clearly relevant in order to understand better its influence on bone turnover and bone loss.

Few studies have been carried out in Italy in order to evaluate the prevalance of hypovitaminosis D. Recent data reports a high prevalence of vitamin D deficiency among free-living postmenopausal women from the area of Milan (Bettica et al. 1997), confirming previous results on elderly subjects with chronic diseases or living in areas of northern Italy with short periods of sunlight (Rossini et al. 1990).

The aim of the present study was to investigate the prevalence and seasonal variation of hypovitaminosis D in free-living normal subjects and hospitalized patients from the area of Rome, in central Italy.

\section{Materials and methods}

We studied 297 subjects in total, 131 in February and 166 in July 1997. The subjects were recruited from the following four groups: (a) young healthy blood donors (February, $n$ 47, mean age $35 \cdot 1$ (SD 10.5) years and July, $n 41$, mean age 34.9 (SD 9.52) years); (b) healthy postmenopausal women (February, $n$ 25, mean age 62.28 (SD 6.59) years and July, $n$ 22, mean age 62.36 (SD 10.41) years); (c) inpatients with various medical diseases (February, $n$ 42, mean age 69.60 (SD 9.93) years, mean hospitalization time 15.73 (SD 22.53) d and July, $n$ 46, mean age 61.6 (SD 14.7) years, mean hospitalization time 10.9 (SD 8.9) d); (d) inpatients engaged in long-term rehabilitation programmes because of various neurological disorders (February, $n$ 17, mean age 73.76 (SD 4.41) years, mean hospitalization time 47.18 (SD 24.23) d and July, $n$ 45, mean age 74.7 (SD 7.7) years, mean hospitalization time 61.0 (SD 32.2) d). In group (d), during the month of July, we also studied twelve patients, mean age 39.75 (SD 19.0) years, mean hospitalization time 475.5 (SD 402.0) d (range 205-1330 d), whose diagnosis was a vegetative state (awake coma) secondary to a traumatic or anoxic encephalopathy. Informed consent was obtained from all eligible subjects or their relatives. Healthy blood donors and postmenopausal women were not taking any drug known to interfere with vitamin D metabolism, while patients were included in the study independently of diseases and/or medication use.

There was no significant seasonal difference in mean age between groups. However, in patients admitted to a general hospital (group (c)) mean age was higher in winter $(P<$ $0 \cdot 005)$. There was no seasonal difference in mean hospitalization time between the two groups of inpatients ((c) and (d)).

In all subjects and patients serum levels of $25(\mathrm{OH}) \mathrm{D}$ were measured by radioimmunoassay (Incstar Co., Stillwater, MN, USA) (Hollis et al. 1993). The assay consists of a two-step procedure: the first step involves a rapid extraction of $25(\mathrm{OH}) \mathrm{D}$ and other hydroxylated metabolites with acetonitrile; following extraction, the treated sample is then assayed using an equilibrium radioimmunoassay procedure, based on an antibody with specificity to $25(\mathrm{OH}) \mathrm{D}$. In our laboratory the intra- and interassay $\mathrm{CV}$ were $8 \cdot 1$ and $10.2 \%$ respectively.

\section{Statistical methods}

Data are presented as means and standard deviations. Correlations between variables were tested using linear regression analysis. Means were compared using Student's $t$ test for two groups or one-way ANOVA for more groups.

\section{Results}

Table 1 shows mean values of serum 25(OH)D levels obtained for each group both in winter and in summer time; no data were collected during February for patients with awake coma and thus they were excluded from inferential statistics. The ANOVA showed significant differences of $25(\mathrm{OH}) \mathrm{D}$ concentrations between groups

\begin{tabular}{|c|c|c|c|c|}
\hline \multirow[t]{2}{*}{ Time of study ... } & \multicolumn{2}{|c|}{ February } & \multicolumn{2}{|c|}{ July } \\
\hline & Mean & SD & Mean & SD \\
\hline Young blood donors & \multicolumn{2}{|c|}{$(n 47)$} & \multicolumn{2}{|c|}{$(n 41)$} \\
\hline Postmenopausal women & \multicolumn{2}{|c|}{$(n 25)$} & \multicolumn{2}{|c|}{$(n 22)$} \\
\hline Inpatients with medical diseases & \multicolumn{2}{|c|}{$(n 42)$} & \multicolumn{2}{|c|}{$(n 46)$} \\
\hline Inpatients engaged in long-term rehabilitation programmes & \multirow{2}{*}{\multicolumn{2}{|c|}{$(n 17)$}} & \multicolumn{2}{|c|}{$(n 45)$} \\
\hline Inpatients with awake coma & & & 62.9 & $25 \cdot 8$ \\
\hline
\end{tabular}

Mean values were significantly different from those for subjects studied in February: ${ }^{* *} P<0 \cdot 0001$. 
Table 2. Prevalence of hypovitaminosis D (\%) in summer and winter time in healthy subjects and hospitalized patients

\begin{tabular}{lcr}
\hline Time of year ... & February & July \\
\hline Young blood donors & 14.6 & 0.0 \\
Postmenopausal women & 32.0 & 4.5 \\
Inpatients with medical conditions & 71.4 & 29.8 \\
Inpatients engaged in long-term & 82.3 & 57.8 \\
$\quad$ rehabilitation programmes & & \\
\hline
\end{tabular}

$(P<0.0001)$, both in February and in July. Significant seasonal variations $(P<0.0001)$ of serum $25(\mathrm{OH}) \mathrm{D}$ levels were also found for each group, mean values being higher in summer; only patients with longer hospitalization time (group (d)) showed no seasonal variation of mean 25(OH)D levels.

The prevalence of hypovitaminosis D (defined as a serum 25(OH)D level below $30 \mathrm{nmol} / \mathrm{l}$ ) in both winter and summer time is shown in Table 2. For each group a significantly higher prevalence of hypovitaminosis $\mathrm{D}$ was found in winter time compared with summer time $(P<0 \cdot 001)$, the percentage being unexpectedly high in postmenopausal women (32\%); moreover, in both seasons, inpatients were found to be at high risk of hypovitaminosis $\mathrm{D}$, particularly those with long-term hospitalization (group (d)).

Furthermore, we found significant negative correlation between the length of hospitalization and serum $25(\mathrm{OH}) \mathrm{D}$ levels both in summer $(n 91, r-0.363, P<0.001)$ and in winter ( $n$ 59, $r-0.236, P<0 \cdot 01)$. A significant linear negative correlation was found between age and serum levels of 25(OH)D, both in February ( $n$ 131, $r-0.454$, $P<0.0001)$ and in July ( $n 154, r-0.625, P<0.0001)$.

\section{Discussion}

To our knowledge, this is the first study assessing vitamin $\mathrm{D}$ status in a sample of both adult general population and hospitalized patients living in central Italy. Epidemiological studies investigating the importance of hypovitaminosis D in Italy are few. In fact, in the SENECA study (van der Wielen et al. 1995), data regarding Italy are not representative, because only twenty-five subjects were enrolled. Other studies carried out in northern Italy have demonstrated that, especially in winter, the prevalence of hypovitaminosis D is unexpectedly high, not only in elderly people with chronic disease (Rossini et al. 1990) but also in free-living postmenopausal women (Bettica et al. 1997).

As previously reported (Chapuy et al. 1983; Tsai et al. 1987), serum 25(OH)D concentrations progressively decrease with advancing age independently of season. Moreover, we found a progressive significant decrease in mean values of serum $25(\mathrm{OH}) \mathrm{D}$ among groups examined, both in February and in July. This finding, among other factors, can be partly ascribed to the progressive increase of mean age observed from group (a) to group (d). In this context it is important to emphasize that we found an unexpectedly high mean value of $25(\mathrm{OH}) \mathrm{D}$ (62.9 (SD $25.8) \mathrm{nmol} / \mathrm{l}$; range $18.52-90.22 \mathrm{nmol} / \mathrm{l}$ ) in the twelve patients with vegetative state, despite being characterized by the longer hospitalization time. This finding confirms that ageing is one of the main determinants of vitamin $\mathrm{D}$ status, because patients with awake coma were much younger than other inpatients. However, the better dietary intake in these patients, whose enteral nutrition included multivitamin solutions, should also be taken into account; indeed, such solutions contain at least $3 \cdot 0-4 \cdot 5 \mu \mathrm{g}$ vitamin D daily, which is approximately the amount recently recommended as an adequate intake for people aged 19-50 years (Utiger, 1998).

As in previous reports (Juttmann et al. 1981; Krall et al. 1989; Woitge et al. 1998), we also found a significant seasonal variation in serum $25(\mathrm{OH}) \mathrm{D}$ levels $(P<0 \cdot 0001)$ in both healthy young subjects and postmenopausal women, with higher values in summer. In patients admitted to a general hospital we still found a seasonal variation of vitamin $\mathrm{D}$, with lower mean values of $25(\mathrm{OH}) \mathrm{D}$ in February compared with July. This finding, in our opinion, could partly be ascribed to the younger mean age of these patients studied in summer; alternatively, since their period of hospitalization was very short, we should consider these patients as being more representative of the general population, at least as far as lifestyle features are concerned. Conversely, in longstay patients (group (d)) the lack of sunshine exposure resulted in no seasonal variation of $25(\mathrm{OH}) \mathrm{D}$ levels. This finding is in disagreement with results reported in residents of long-term care facilities (Liu et al. 1997). This discrepancy could be ascribed to the different characteristics of patients examined, including affecting diseases, medications used and limitation in mobility with rare outdoor exposure.

The prevalence of hypovitaminosis D (defined as a serum 25(OH)D level below $30 \mathrm{nmol} / \mathrm{l})$ is reported in Table 2 . The choice of $30 \mathrm{nmol} / \mathrm{l}$ as a cut-off value for defining hypovitaminosis is in agreement with the threshold considered in several studies carried out in different European countries (van der Wielen et al. 1995; Chapuy et al. 1996, 1997; Lips et al. 1996). A greater percentage of prevalence would have been obtained if the hypovitaminosis was defined at a higher threshold as has been recently suggested (Malabanan et al. 1998). The results are unexpected, especially as far as the healthy population is concerned; interestingly, in postmenopausal women the high percentage of hypovitaminosis D in winter (about $32 \%$ ) was the same as that reported recently in free-living postmenopausal women from the area of Milan (Bettica et al. 1997). This finding is intriguing, because in northern Italy the supply of sunshine is limited to a shorter period of the year compared with the centre of the country. One possible explanation might be that as dairy products are not fortified with vitamin D and the use of nutritional supplements is uncommon in Italy, estimated vitamin D intake (about 3-5 $\mu \mathrm{g} / \mathrm{d}$ ) is below the amount recommended $(10 \mu \mathrm{g} / \mathrm{d})$ (Standing Committee on the Scientific Evaluation of Dietary Reference Intakes, 1997). We can hypothesize that other physiological and/or lifestyle characteristics may influence serum 25(OH)D concentrations (Chapuy et al. 1996).

All hospitalized patients, both in summer and in winter, are characterized by the highest prevalence of hypovitaminosis D, especially the older patients. Medical inpatients may be at risk for vitamin D deficiency, 
especially residents of nursing homes and elderly people (Goldray et al. 1989; Komar et al. 1993; Gloth et al. 1995; Chapuy et al. 1996). However, the results of our study clearly demonstrate that younger patients admitted to a general hospital for various medical diseases also exhibit a high prevalence of hypovitaminosis $\mathrm{D}$, reaching $72 \%$ in winter. This finding is in agreement with results recently reported in the USA (Shane et al. 1997; Thomas et al. 1998), demonstrating that the problem of vitamin D deficiency in patients needing admission to hospital is more widespread than previously appreciated.

In the group of patients engaged in long-term rehabilitation programmes we found the highest prevalence of hypovitaminosis $\mathrm{D}$, ranging from $57.8 \%$ in summer to $82.3 \%$ in winter. The older age, the presence of neurological disease causing reduced mobility and/or the requirement of anticonvulsant-drug therapy are probably responsible for an increased risk of vitamin D deficiency in this group of inpatients.

In conclusion, the results of the present study clearly provide evidence of the impact of hypovitaminosis D on medical practice in our country and underline the importance of serum 25(OH)D measurement. Foodstuff fortification and supplement use must be considered in order to prevent the negative effect of vitamin D deficiency on skeletal integrity.

\section{References}

Akesson K, Lau KHW \& Baylink DJ (1997) Rationale for active vitamin D analog therapy in senile osteoporosis. Calcified Tissue International 60, 100-105.

Bettica P, Bevilacqua M, Vago T \& Norbiato G (1997) High prevalence of vitamin D deficiency among free-living postmenopausal women in Northern Italy. Italian Journal of Mineral \& Electrolyte Metabolism 11, Suppl. 1, 3.

Chapuy MC, Durr F \& Chapuy P (1983) Age-related changes in parathyroid hormone and 25-hydroxycholecalciferol levels. Journal of Gerontology 1, 19-22.

Chapuy MC, Preziosi P, Maamer M, Arnaud S, Galan P, Hercberg S \& Meunier PJ (1997) Prevalence of vitamin D insufficiency in an adult normal population. Osteoporosis International 7, 439-443.

Chapuy MC, Schott AM, Garnero P, Hans D, Delmas PD \& Meunier PJ (1996) Healthy elderly French women living at home have secondary hyperparathyroidism and high bone turnover in winter. Journal of Clinical Endocrinology and Metabolism 81, 1129-1133.

Fraser DR (1995) Vitamin D. Lancet 345, 104-107.

Gloth FM III, Gundberg CM, Hollis BW, Haddad JG Jr \& Tobin JD (1995) Vitamin D deficiency in homebound elderly persons. Journal of the American Medical Association 274, 1683-1686.

Goldray D, Mizrahi-Sasson E, Merdler C, Edelstein-Singer M, Algoetti A, Eisenberg Z, Jaccard N \& Weisman Y (1989) Vitamin D deficiency in elderly patients in a general hospital. Journal of the American Geriatrics Society 7, 589-592.

Hollis BW (1996) Assessment of vitamin D nutritional and hormonal status: what to measure and how to do it. Calcified Tissue International 58, 4-5.

Hollis BW, Kamerud JQ, Selvaag SR, Lorenz JD \& Napoli JL (1993) Determination of vitamin D status by radioimmunoassay with ${ }^{125}$ I-labeled tracer. Clinical Chemistry 39, 529-533.

Jacques PF, Felson DT, Tucker KL, Mahnken B, Wilson PWF, Rosenberg IH \& Rush D (1997) Plasma 25-hydroxyvitamin D and its determinants in an elderly population sample. American Journal of Clinical Nutrition 66, 929-936.

Juttmann JR, Uisser TJ, Buurman C, De Kam E \& Birkenhager JC (1981) Seasonal fluctuations in serum concentrations of vitamin D metabolites in normal subjects. British Medical Journal 282, 1349-1352.

Keane EM, Healy M, O’Moore R, Coakley D \& Walsh JB (1995) Hypovitaminosis D in the healthy elderly. British Journal of Clinical Practice 49, 301-303.

Khaw KT, Sneyd MJ \& Compston J (1992) Bone density, parathyroid hormone and 25-hydroxyvitamin D concentrations in middle aged women. British Medical Journal 305, 273-277.

Komar L, Nieves J, Cosman F, Rubin A, Shen V \& Lindsay R (1993) Calcium homeostasis of an elderly population upon admission to a nursing home. Journal of the American Geriatrics Society 41, 1057-1064.

Krall EA, Sahyoun N, Tannenbaum S, Dallal GE \& DawsonHughes B (1989) Effect of vitamin D intake on seasonal variations in parathyroid hormone secretion in postmenopausal women. New England Journal of Medicine 321, 1777-1783.

Lips P, Graafmans WC, Ooms ME, Bezemer PD \& Bouter LM (1996) Vitamin D supplementation and fracture incidence in elderly persons. A randomized, placebo-controlled clinical trial. Annals of Internal Medicine 124, 400-406.

Liu BA, Gordon M, Labranche JM, Murray TM, Vieth R \& Shear NH (1997) Seasonal prevalence of vitamin D deficiency in institutionalized older adults. Journal of the American Geriatrics Society 45, 598-603.

McKenna MJ (1992) Differences in vitamin D status between countries in young adults and the elderly. American Journal of Medicine 93, 69-77.

Malabanan A, Veronikis E \& Holick MF (1998) Redefining vitamin D insufficiency. Lancet 351, 805-806.

Parfitt AM, Gallagher JC, Heaney RP, Johnston CC, Neer R \& Whedon GD (1982) Vitamin D and bone health in the elderly. American Journal of Clinical Nutrition 36, 1014-1031.

Quesada-Gomez JM, Alonso J \& Bouillon R (1996) Vitamin D insufficiency as a determinant of hip fractures. Osteoporosis International Suppl. 3, S42-S47.

Rossini M, Perbellini S, Lazzarin M, Adami S, Bertoldo F \& Lo Cascio V (1990) Incidenza di ipovitaminosi D nel Nord Italia (Incidence of hypovitaminosis D in northern Italy). Italian Journal of Mineral and Electrolyte Metabolism 4, $13-17$.

Shane E, Mancini D, Aaronson K, Silverberg SJ, Seibel MJ, Addesso V \& McMahon DJ (1997) Bone mass, vitamin D deficiency, and hyperparathyroidism in congestive heart failure. American Journal of Medicine 103, 197-207.

Sherman SS, Hollis BW \& Tobin JD (1990) Vitamin D status and related parameters in a healthy population: the effects of age, sex, and season. Journal of Clinical Endocrinology and Metabolism 71, 405-413.

Standing Committee on the Scientific Evaluation of Dietary References Intakes, Institute of Medicine (1997) Dietary reference intakes: calcium, phosphorus, magnesium, vitamin D, and fluoride. Washington, DC: National Academy Press.

Thomas MK, Lloyd-Jones DM, Thadhani RI, Shaw AC, Deraska DJ, Kitch BT, Vamvakas EC, Dick IM, Prince RL \& Finkelstein JS (1998) Hypovitaminosis D in medical inpatients. New England Journal of Medicine 338, 777-783.

Tsai KS, Wahner HW, Offord KP, Melton LJ III, Kumar R \& Riggs BL (1987) Effect of aging on vitamin D stores and bone density in women. Calcified Tissue International 40, 241-243.

Utiger RD (1998) The need for more vitamin D. New England Journal of Medicine 338, 828-829.

van der Wielen RPJ, Löwick MRH, van der Berg H, de Groot L, Haler J, Moreiras O \& van Staveren WA (1995) Serum vitamin 
D concentrations among elderly people in Europe. Lancet 346, 207-210.

Villareal DT, Civitelli R, Chines A \& Avioli LV (1991) Subclinical vitamin D deficiency in postmenopausal women with low vertebral bone mass. Journal of Clinical Endocrinology and Metabolism 72, 628-634.
Woitge HW, Scheidt-Nave C, Kissling C, Leidig-Bruckner G, Meyer K, Grauer A, Scharla SH, Ziegler R \& Seibel MJ (1998) Seasonal variation of biochemical indexes of bone turnover: results of a population based study. Journal of Clinical Endocrinology and Metabolism 83, 68-75. 


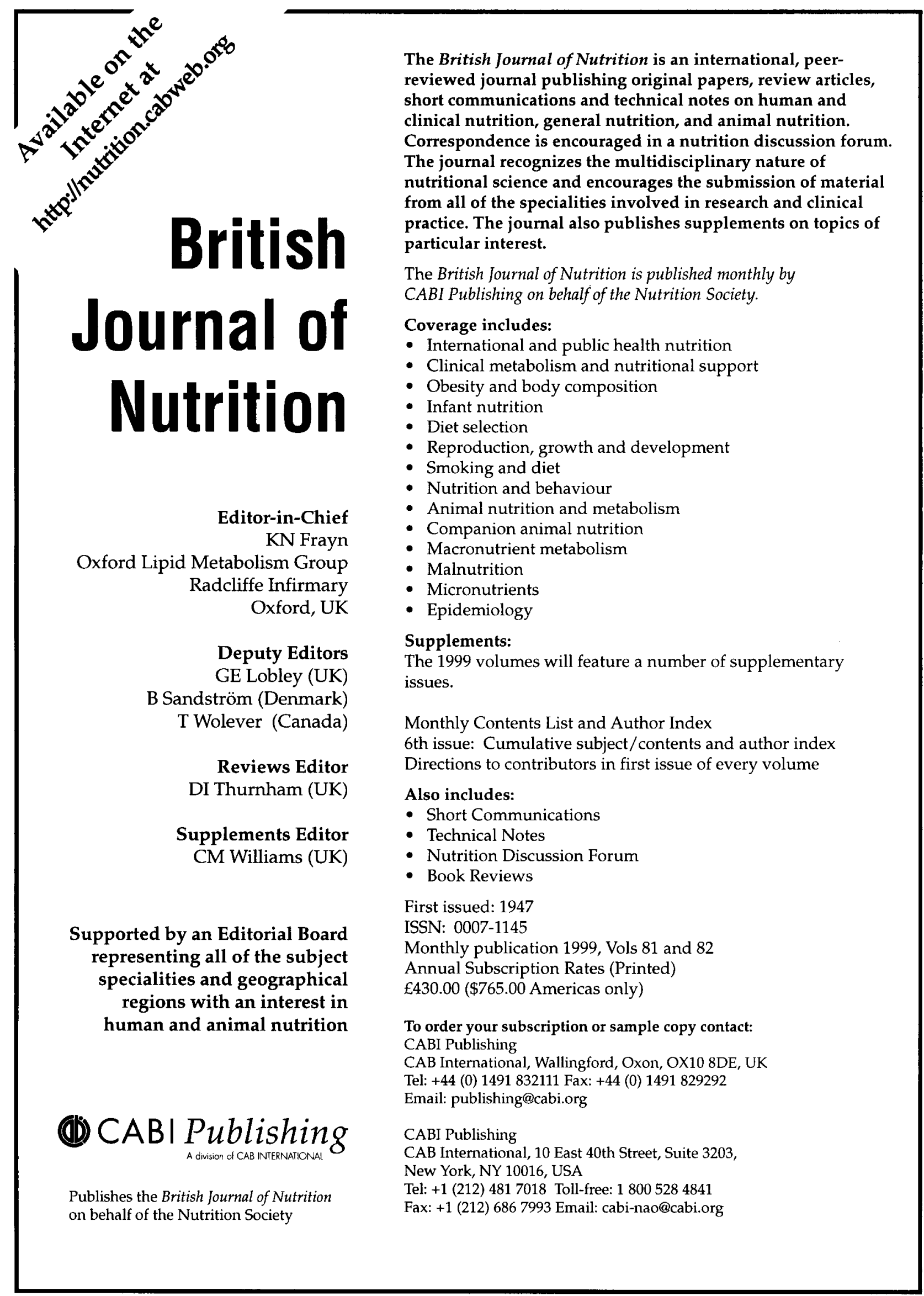

